\title{
The Influence of Environmental Stress Cracking (ESC) and Gamma Irradiation on the Mechanical Properties of Polycarbonate: Study of Synergistic Effects
}

\author{
Pietro Paolo de O. e Silva $a^{*}$ (, Patricia L. B. Araujo ${ }^{b}$, Thaises Brunelle Santana de Limac, \\ Elmo S. Araujoc \\ ${ }^{a}$ Instituto Federal de Pernambuco - IFPE, Departamento de Física, Av. Prof. Luiz Freire, \\ 500, 50740-545, Recife, PE, Brasil. \\ ${ }^{b}$ Universidade Federal de Pernambuco - UFPE, Departamento de Engenharia Biomédica, Av. \\ Jornalista Anibal Fernandes, s/n, Area II, Cidade Universitária, 50740-560, Recife, PE, Brasil. \\ ${ }^{c}$ Universidade Federal de Pernambuco - UFPE, Departamento de Energia Nuclear, Av. Prof. Luiz \\ Freire, 1000, 50740-545, Recife, PE, Brasil.
}

Received: July 06, 2021; Revised: August 30, 2021; Accepted: October 8, 2021

\begin{abstract}
Polycarbonate is an engineering polymer due its outstanding properties and is widely used in several different applications. In some of these applications it can be exposed to certain liquids/solvents. In many cases, this liquid exposure may cause an effect known as Environmental Stress Cracking (ESC), which may lead to crack formation on the polymer surface and consequent reduction of its mechanical resistance, with loss of lifetime. On the other hand, polycarbonate medical supplies are often exposed to gamma rays in the radio-sterilization process, at doses up to $25 \mathrm{kGy}$. This exposure causes main chain scissions. In this present work, the viscosity average molecular weight decreased about $10 \%$ at $25 \mathrm{kGy}$. Elongation at break was drastically affected by ESC phenomenon. When simultaneously exposed to the ESC agents (methanol or isopropanol) and gamma radiation, combined effects of both takes place. Moreover, the stress relaxation rate of $\sim 1000 \mathrm{~Pa} / \mathrm{s}$ (air or methanol) and $\sim 2200 \mathrm{~Pa} / \mathrm{s}$ (isopropanol) at the dose of $100 \mathrm{kGy}$, suggests strong influence of isopropanol as surfactant on PC. Results of elongation at break and stress relaxation rate were reliable data to evaluate ESC and radiolytic effects on PC.
\end{abstract}

Keywords: Polycarbonate, Gamma radiation, ESC, Mechanical properties, Degradation.

\section{Introduction}

Polycarbonate (PC) is a polymer that exhibits several interesting properties that make it a widely employed polymer in an extreme variety of applications. Among these features are the exceptional mechanical, optical and thermal properties $^{1-6}$. In some cases, the PC's may have contact with surfactants liquids, which can cause modifications in their surfaces leading to crazes and cracks formation. These crazes and cracks will weaken the polymer and can lead it to a fracture, shortening its lifetime. Such effect is known as ESC (that stands for environmental stress cracking) and it has been the object of study in a broad spectrum of different polymeric systems ${ }^{7-9}$. One estimates that ESC is responsible for approximately $25 \%$ of all serious premature failures of plastic-based components. Almost $90 \%$ of these failures occur in amorphous (glassy) polymers such as polystyrene, poly(methyl methacrylate), and polycarbonate ${ }^{10-12}$. In some cases, even an apparent inoffensive liquid can act as an ESC agent in case of having external mechanical stress concomitantly with liquid contact ${ }^{13}$.

In the late of the 50's, it was showed considerable interest in the potential of using high energy radiation to modify the polymer features, inducing crosslinking or main chain scissions ${ }^{14,15}$. Nowadays, the use of ionizing

*e-mail: pietropaolo@recife.ifpe.edu.br radiation in polymer industry is mainly related with radio sterilization of medical artifacts and induced crosslinking of wires and cables ${ }^{3,9,16}$. However, in nuclear power plants or nuclear medicine laboratories, objects made or that contain polycarbonate may be exposed to gamma radiation ${ }^{17-23}$. Thus, to investigate polymers that are irradiated in a variety of conditions provides detailed information about many processes that occur between the initial energy absorption and the final physical and chemical changings.

Irradiated polymers can undergo, besides other effects, mainly main chain scissions or crosslinking and generally they undergo concomitantly both. Depending on the polymer structure and/or irradiation conditions (dose, dose rate, atmosphere, etc.) one effect can be preponderant over the other ${ }^{3}$. Some works reported evidences of main chain scissions on irradiated PC (that can be detected by reduction of the viscosimetric molar mass of the polymer) in all doses ${ }^{3,24}$. Acierno et al. ${ }^{25}$, have reported crosslinking effects at low doses and main chain scissions trend for higher doses on $\mathrm{PC}$ exposed to gamma radiation.

Therefore, because of frequent PC exposure to ESC liquids and gamma radiation, the aim of this present work is to investigate the action of these damage agents and to observe possible synergistic effects of ESC and gamma irradiation on the mechanical properties of Durolon ${ }^{\circledR}$ polycarbonate. 


\section{Experimental Section}

\subsection{Materials}

Durolon PC, Commercial grade (IR2200, in standard formulation containing only processing additives) were manufactured and supplied by Unigel Plásticos S.A (Camaçari/ BA, Brazil). Methanol and 2-propanol (isopropanol) were of analytical grade (Lab-synth Ltda, Brazil) and used as supplied.

\subsection{Samples irradiation}

PC test samples were irradiated in a Co-60 irradiator (GammaCell GC220 MDS Nordion, Canada, dose rate $4.3 \mathrm{kGy} / \mathrm{h}$ ) in air, at room temperature $\left(\mathrm{ca} .28^{\circ} \mathrm{C}\right)$, in doses of $25,50,75,100$ or $200 \mathrm{kGy}$.

\subsection{Viscosity average molecular weight}

This step aims to evaluate radiolysis degradation induced by gamma radiation on the PC samples in all doses described on the previous topic. For comparison, zero dose samples were analyzed as well. The viscosity average molecular weight $\left(M_{V}\right)$ of the samples was determined by intrinsic viscosity $([\eta])^{26}$. Solutions with $0.6 \mathrm{~g} / \mathrm{dL}$ were prepared using chloroform from the test samples in triplicate. The solutions were left under magnetic stirring for $24 \mathrm{~h}$. An Ostwald viscometer $\left(n^{\circ} 50\right)$ was used and the temperature of the system was set at $25 \pm 0.1^{\circ} \mathrm{C}$. The intrinsic viscosity $([\eta])$ was calculated by measuring, at least 10 times, the average efflux time (i.e. the time to the solution pass through the two marks of the viscometer) of the dilute polymeric solution $(t)$ and solvent $\left(t_{0}\right)$ and by using the Equations $1-4^{27,28}$.

$\eta_{\text {rel }}=\eta / \eta_{0} \approx \frac{t}{t_{0}}$

$\eta_{s p}=\eta_{\text {rel }}-1$

$\eta_{\text {red }}=\eta_{s p} / C$

$[\eta]=\frac{\left[2\left(\eta_{s p}-\ln \eta_{r e l}\right)\right]^{1 / 2}}{C}$

Where, $\eta, \eta_{\theta}, \eta_{\text {rel }}, \eta_{s p}, \eta_{\text {red }}$, are solution, solvent, relative, specific, and reduced viscosities, respectively. $C$ is the solution concentration (in chloroform at $0.6 \mathrm{~g} / \mathrm{dL}$ ). The Equations 1 to 4 have validity to dilute polymer solution $\left(\eta_{\text {rel }}<2\right)^{29}$.

Finally, the average viscosity molecular weight, Mv, for each sample was determined from Mark-Houwink-Sakurada equation $^{27-30}$.

$[\eta]=K\left(M_{v}\right)^{a}$

Where $K$ and $a$ constants depend on the solvent-polymer system and the temperature. For the used conditions, $K$ and $a$ are $30.1 \times 10^{-5} \mathrm{dL} / \mathrm{g}$ and 0.74 , respectively ${ }^{31}$.

\subsection{Tensile strength test}

Stress-strain curves were obtained in an EMIC DL1000 mechanical test machine, using a crosshead speed of 2 and $20 \mathrm{~mm} / \mathrm{min}$, for comparison, under three conditions: in air, dampened with methanol, or with isopropanol. Non-irradiated samples, samples exposed to $100 \mathrm{kGy}$ and $200 \mathrm{kGy}$ of gamma radiation were tested in each condition. Four samples test ('dogbone' shape) were used in each test $^{32}$. The application of each ESC liquid (methanol and isopropanol) was made with a tissue paper, by continuously wetting the sample test neck.

\subsection{Stress relaxation}

Stress relaxation experiments were performed in order to evaluate the combined effects of ESC and gamma irradiation on PC, by using an EMIC DL1000 mechanical test machine. As suggested by Sousa ${ }^{33}$, initially it was used a load of $1000 \mathrm{~N}$ at $5 \mathrm{~mm} / \mathrm{min}$ crosshead speed, equivalent to half of the tensile strength at yield point (stress-strain curve) in order to get the better load stopping point to set the stress relaxation experiment. However, the stress relaxation experiment on PC was performed using load of $1500 \mathrm{~N}(\sim 18 \mathrm{MPa})$ for promoting better sensibility. Then, the stress decay at constant strain along the time was measured. The time for reaching the maximum stress $(\sim 18 \mathrm{MPa})$ was ca. $1 \mathrm{~min}$ and total time for this test was $25 \mathrm{~min}$. The experiments were performed under three conditions: air, methanol and isopropanol. Non-irradiated samples and samples irradiated with gamma radiation with doses of 50, 100 and $200 \mathrm{kGy}$ were used in each condition. The application of each ESC liquid was made with a tissue paper, by continuously wetting the sample neck, from the point where the maximum stress was reached (i.e. the stopping point). The stress relaxation rate $(\dot{\sigma})$ was calculated as follow:

$\dot{\sigma}=\frac{\Delta \sigma}{\Delta t}$

Where $\Delta \sigma$ is the stress variation along the time and $\Delta \mathrm{t}$ is time interval between the load stopping point (i.e. the time when the machine reaches the programmed maximum stress) and the end of the measurement.

\subsection{Scanning electron microscopy - SEM}

SEM analyses were performed on gold-coated samples on a Quanta equipment, model 200FEG.

\section{Results and Discussion}

\subsection{Viscometry}

As early reported by Araújo et al. ${ }^{3}$, main chain scissions are the predominant effect on Durolon PC exposed to gamma radiation, observed by the decrease of the intrinsic viscosity at different doses. Many studies pointed that main chain scissions on irradiated PC take place on the carbonyl $(\mathrm{C}=\mathrm{O})$ group ${ }^{3,24,34,35}$. In this work, it was observed decrease in the viscosity average molecular weight $\left(M_{v}\right)$ more accentuated at doses of $25 \mathrm{kGy}$ and $50 \mathrm{kGy}$ compared with the non-irradiated samples and for higher doses above $75 \mathrm{kGy}$ the relative decrease is less accentuated (Figure 1). These results are in agreement with Araújo et al. ${ }^{3}$. 


\subsection{Gamma irradiation effects on mechanical properties of $P C$}

Tables 1 and 2, column 2, show the mechanical properties of tensile stress at break (Table 1) and elongation at break (Table 2) for PC exposed to gamma irradiation. The tensile experiments were performed after irradiation of the samples at different conditions: air, under methanol and isopropanol exposure. Clearly, only the gamma irradiation itself did not significantly change the tensile stress and elongation at break on PC, since that occurred overlay of standard deviation in the measurements. Similar behavior was observed by Melo et al. ${ }^{36}$ to Lexan PC and by Araújo et al. ${ }^{3}$ for Durolon PC. These results confirm that the mechanical resistance of $\mathrm{PC}$ is maintained even in high doses of ionizing radiation. In general, polymers with aromatic groups in their molecular structures present high resistance to ionizing radiation. It is worth to note that different crosshead speeds used on present work ( 2 and $20 \mathrm{~mm} / \mathrm{min}$ ) also did not significantly change the mechanical results.

\subsection{Environmental Stress Cracking (ESC) on PC}

In this section it was analyzed the ESC phenomenon on PC with methanol and isopropanol as surfactant liquids. Tables 1 and 2, columns 3 and 4, show the results of mechanical

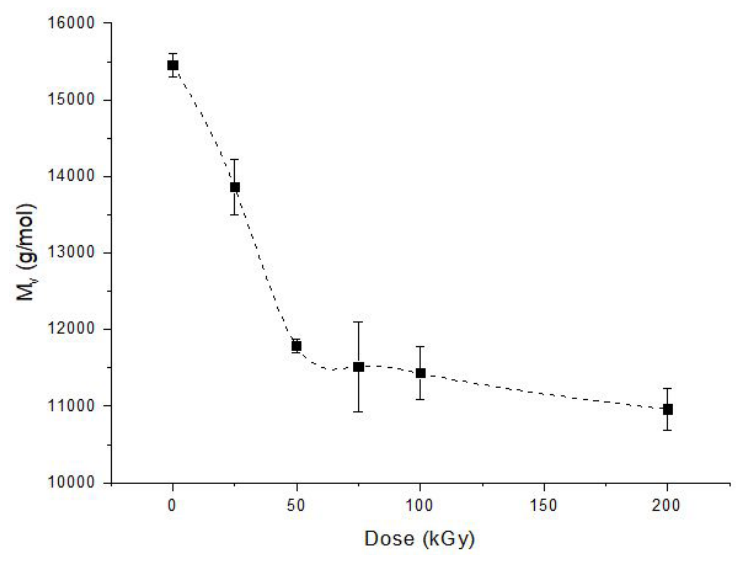

Figure 1. Viscosity average molecular weight for PC as a function of gamma absorbed dose. properties of $\mathrm{PC}$ exposed to gamma radiation upon methanol and isopropanol exposure. Tensile stress at break does not significantly change for any condition, air (without liquid), methanol and isopropanol. On the other hand, elongation at break showed to be a good indicator to evaluate ESC on polymeric systems. This property presented decreased over $70 \%$ and $80 \%$ (in relative values) for methanol and isopropanol, respectively, compared with non-irradiated PC. This is a typical feature of ESC phenomenon (see Figure 2) on polymer materials. Methanol and isopropanol act as surfactant liquids, producing crazes, cracking and a ductile-to fragile changing behavior ${ }^{37-41}$. Moreover, the gamma irradiation on PC under the surfactants, at doses of 100 and $200 \mathrm{kGy}$, did not affect the ESC phenomenon on PC.

Figure 2 shows a SEM of the non-irradiated PC after tensile strength test ( $2 \mathrm{~mm} / \mathrm{min}$ crosshead speed) upon methanol exposure. In the figure is shown a sample surface detail, indicating a crack and in the crack tips some crazes, having the typical micro-fibrillations as highlighted in the picture ${ }^{7,8,41-44}$. The drastic decrease on the strain ability of $\mathrm{PC}$ upon methanol action is an indicative that methanol is a strong surfactant, having considerable ESC action on PC, as shown in Table 2. The crazes induced by ESC effect are cracks precursors, leading the PC to premature fracture. Jansen ${ }^{45}$ highlighted that combined action of stress and solvents can accelerate the fracture and fail of the polymeric material.

\subsection{Stress relaxation tests}

Figure 3 shows stress-strain curves for PC under air, methanol and isopropanol. This late presented the most aggressive ESC action in the tensile tests, leading the sample to a severe embrittlement, which allow it to break prematurely. Some manufacturers indicate the use of isopropanol for cleaning PC artifacts, however, without any warning about the physical damages on PC material under tensile stress ${ }^{46,47}$.

Stress relaxation tests were performed in order to evaluate the combined effect of ESC and gamma irradiation on PC. Many authors have attributed the efficiency of this experiment on the assessment of measures of the synergistic action of ESC and radiolysis on polymeric systems ${ }^{33,48-50}$. Stress relaxation is related to the fact that when a polymeric sample undergoes a constant strain the stress load tends to decay along the time due to its viscoelasticity. This behavior

Table 1. Tensile stress at break (MPa) of PC under air, methanol and isopropanol as function of absorbed dose, with crosshead speeds at 2 and $20 \mathrm{~mm} / \mathrm{min}$.

\begin{tabular}{|c|c|c|c|c|c|c|}
\hline \multirow{2}{*}{ Dose (kGy) } & \multicolumn{2}{|c|}{ Air (without liquid) } & \multicolumn{2}{|c|}{ Methanol } & \multicolumn{2}{|c|}{ Isopropanol } \\
\hline & $2(\mathrm{~mm} / \mathrm{min})$ & $20(\mathrm{~mm} / \mathrm{min})$ & $2(\mathrm{~mm} / \mathrm{min})$ & $20(\mathrm{~mm} / \mathrm{min})$ & $2(\mathrm{~mm} / \mathrm{min})$ & $20(\mathrm{~mm} / \mathrm{min})$ \\
\hline 0 & $27.25 \pm 2.50$ & $28.25 \pm 4.11$ & $25.75 \pm 2.22$ & $25.50 \pm 0.58$ & $22.67 \pm 1.15$ & $22.75 \pm 2.06$ \\
\hline 100 & $25.33 \pm 2.08$ & $29.00 \pm 2.00$ & $24.33 \pm 0.58$ & $24.67 \pm 1.15$ & $25.67 \pm 0.58$ & $22.67 \pm 0.58$ \\
\hline 200 & $25.67 \pm 0.58$ & $27.00 \pm 2.94$ & $28.00 \pm 1.73$ & $25.50 \pm 0.71$ & $27.00 \pm 0.00$ & $23.00 \pm 1.00$ \\
\hline
\end{tabular}

Table 2. Elongation (\%) at break of PC under air, methanol and isopropanol as function of absorbed dose, with crosshead speeds at 2 and $20 \mathrm{~mm} / \mathrm{min}$.

\begin{tabular}{ccccccccc}
\hline \multirow{2}{*}{ Dose $(\mathrm{kGy})$} & \multicolumn{2}{c}{ Air (without liquid) } & & \multicolumn{2}{c}{ Methanol } & & \multicolumn{2}{c}{ Isopropanol } \\
\cline { 2 - 3 } & $2(\mathrm{~mm} / \mathrm{min})$ & $20(\mathrm{~mm} / \mathrm{min})$ & & $2(\mathrm{~mm} / \mathrm{min})$ & $20(\mathrm{~mm} / \mathrm{min})$ & & $2(\mathrm{~mm} / \mathrm{min})$ & $20(\mathrm{~mm} / \mathrm{min})$ \\
\hline 0 & $78.12 \pm 10.7$ & $66.30 \pm 15.05$ & & $20.08 \pm 3.43$ & $19.10 \pm 3.74$ & & $10.28 \pm 0.66$ & $12.46 \pm 2.51$ \\
\hline 100 & $59.13 \pm 8.25$ & $82.35 \pm 14.73$ & & $16.37 \pm 4.93$ & $13.76 \pm 2.39$ & & $8.95 \pm 0.54$ & $10.75 \pm 0.40$ \\
\hline 200 & $60.19 \pm 2.96$ & $67.00 \pm 20.77$ & & $8.67 \pm 0.57$ & $11.77 \pm 2.39$ & & $6.57 \pm 0.10$ & $10.22 \pm 0.66$ \\
\hline
\end{tabular}


indicates the capacity of polymeric materials to accommodate stress load from internal energy release behavior ${ }^{51-55}$. This phenomenon is well-known and expected for polymers, however if it is possible to separate this effect from the additional relaxation due to liquid exposure it could be a simple test for ESC measurements. The molecule relaxation due to ESC agent contact is a consequence of local plasticization effects, which increase the molecular mobility in the craze region and allow higher liquid diffusion ${ }^{56}$. Therefore, the higher the interaction between the fluid and the polymer, the greater is stress relaxation of the material. In this type of simple relaxation test, the tensile machine applies a tensile load in a constant rate until reach the stopping point. Once this point is reached, the machine stops increasing the stress and starts measuring the decay of this stress along the time under constant strain. The method is discussed in more detail

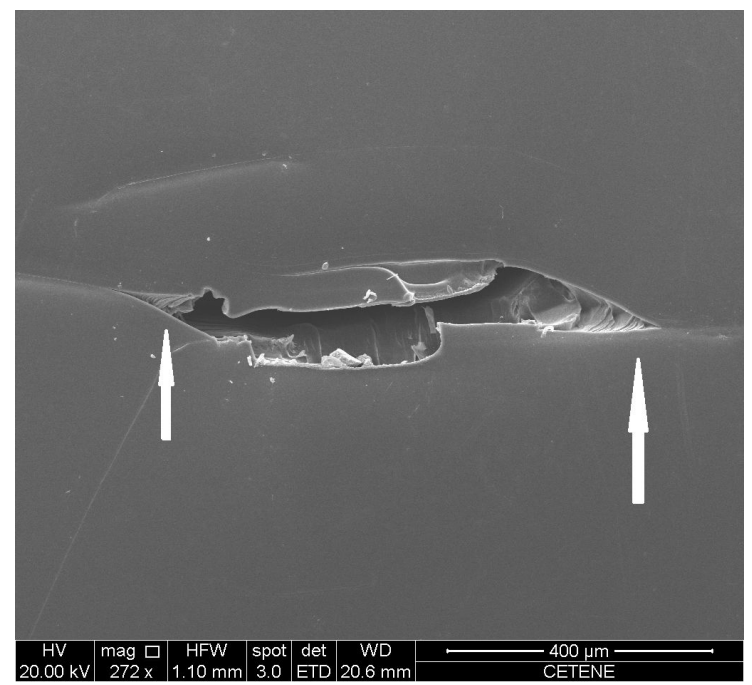

Figure 2. SEM image of a crack and crazes (pointed by arrows) in the PC surface after tensile strength test under methanol exposure.

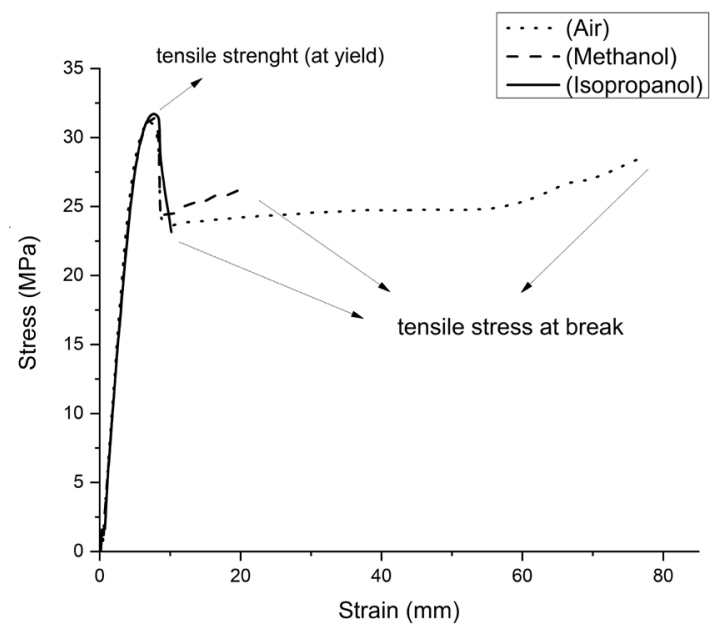

Figure 3. Tensile strength curves $(2 \mathrm{~mm} / \mathrm{min})$ for Durolon PC in three different environments, showing the most aggressive ESC action of isopropanol. in the experimental section above. The advantages of this method compared to the creep tests or frequency sweep tests for relaxation tests are shorter test times and the fact that it is possible to perform in simple tensile strength machines. Figure 4 shows relaxation curves for the three environments: air, methanol and isopropanol for the non-irradiated PC. Methanol practically did not change the relaxation behavior of the non-irradiated PC compared with air environment. In contrast, isopropanol promoted an additional relaxation, verified by a more intense decay in the stress along the time, i.e. a higher stress relaxation rate $(\dot{\sigma})$. This behavior is an indication of stress energy released due to formation and propagation of cracks and consequent decrease of the applied stress under constant strain.

\subsection{Combined effect of ESC (methanol and isopropanol) and gamma irradiation on $P C$}

To verify the combined effect of ESC agent and gamma irradiation on PC, Figure 5 depicts the stress relaxation curves for the three environments (air, methanol and isopropanol) in the irradiated PC at $200 \mathrm{kGy}$. In this case, it is possible to verify that differently from Figure 4 relaxation curves, both methanol and isopropanol acted as amplifier of relaxation rates, indicating that there was combined effect of these phenomena. This combined effect did not occur for all doses in the range tested. A synthesis of the results can be seen in Figure 6 that shows the stress relaxation rates for different doses tested.

Figure 6 shows the stress relaxation rate versus time for PC exposed to gamma radiation in air (without surfactant), methanol and isopropanol. It can be observed that the relaxation rate, for $\mathrm{PC}$ in air, was slightly affected at radiation doses range of $50-200 \mathrm{kGy}$, with increase of $30 \%$ on this property in all range. This result was insignificant to promote any change on tensile stress and elongation properties of $\mathrm{PC}$, as show data from Table 1. By analyzing the graph, considering first the ESC phenomenon $(0 \mathrm{kGy}$ dose), it can be seen that this phenomenon occurred only in isopropanol media, with increase on stress relaxation rate of approximately $100 \%$, whereas methanol remained with similar values of non-irradiated PC at $\sim 750 \mathrm{~Pa} / \mathrm{s}$, i.e., no ESC effect. Investigating combined effects of ESC and

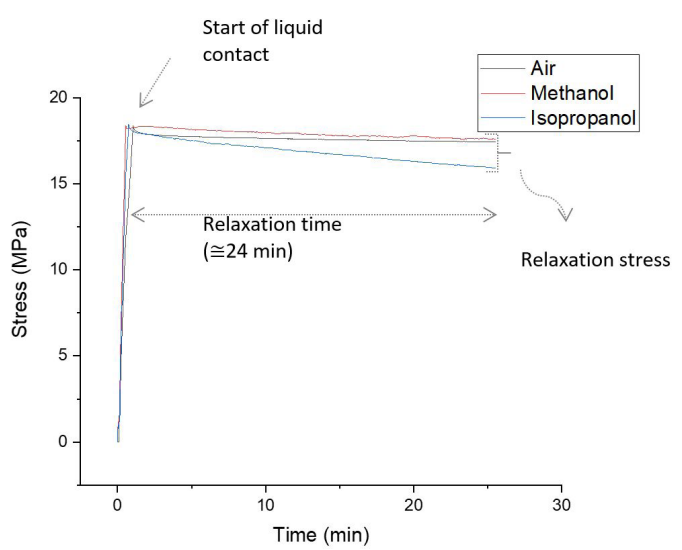

Figure 4. Simple relaxation test curves of non-irradiated PC in three different environments. 


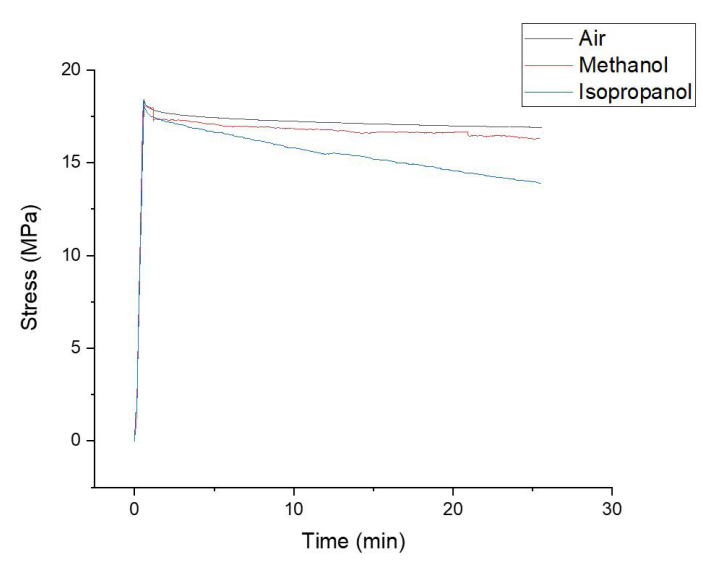

Figure 5. Simple relaxation test curves of $200 \mathrm{kGy} P C$ in three different environments.

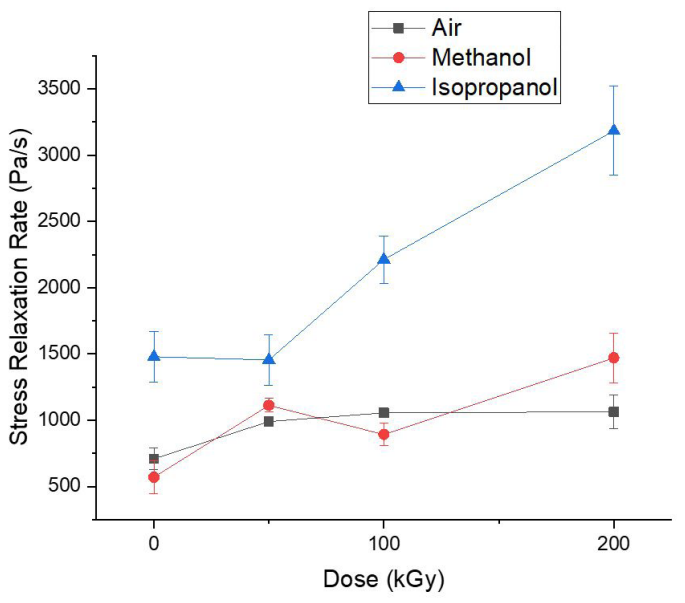

Figure 6. Stress-relaxation rates as a function of absorbed dose for $\mathrm{PC}$ in three different environments.

radiolytic processes by stress relaxation rate, it should be noted that isopropanol presents synergism effect on these damage processes on PC. It is clearly noted an increase on the stress relaxation rate of $120 \%$ and $215 \%$, for doses at 100 and $200 \mathrm{kGy}$, respectively. Methanol showed combined effect only in the dose of $200 \mathrm{kGy}$, with $50 \%$ of increasing. It has been reported in a previous work, that diffusion parameters for methanol performed on non-irradiated and gamma irradiated PC at $100 \mathrm{kGy}$ had no clear differences among them ${ }^{13}$. Timóteo and coworkers ${ }^{50}$, have founded similar behavior for polystyrene (PS) tested by using different alcohols as surfactant agents. They stated that among all the alcohols, isopropanol had the most intense influence on the variation of stress relaxation rates for PS.

The explanation of the severe action of isopropanol in the PC under tensile stress was extensively discussed by the authors in a previous work ${ }^{13}$ and is based on the Hansen solubility parameters. Kjellander $(2008)^{1}$ has used similar approach.

In fact, synergistic effect of ESC and gamma irradiation on polycarbonate under methanol and isopropanol as surfactant liquids is attributed to the main chain scissions induced by radiation, which increase the free volume into polymer matrix. This increase in the free volume allows a greater diffusion of liquids into polymer system, mainly for irradiated PC at doses over $50 \mathrm{kGy}$ upon isopropanol. Similar results were founded by Sousa and coworkers ${ }^{33,48}$.

Therefore, elongation (\%) at break and stress relaxation rate showed sharply that are properties complementary on investigation of ESC and radiolytic process on polymeric systems, with conclusive results about synergistic effects.

\section{Conclusions}

The results obtained on this work showed that main chain scissions induced by gamma irradiation on PC at doses up to $200 \mathrm{kGy}$ did not affect significantly the mechanical properties of the polymer. Elongation (\%) at break is a good indicator to investigate ESC phenomena in polymeric system. This property decreased $70 \%$ and $80 \%$, in relative values, for methanol and isopropanol media, respectively. Stress relaxation rate presented high sensitivity on the investigation of combined effects of ESC and irradiation on PC exposed to methanol (200 kGy) and isopropanol (100 and $200 \mathrm{kGy}$ ). This late showed to be an aggressive ESC agent and its use on cleaning of PC medical artifacts should be strongly revised by the manufacturers. It is suggested that the properties elongation (\%) at break and stress relaxation rate are complementary on ESC investigation and radiolysis processes on polymeric systems.

\section{Acknowledgments}

The authors thank to Leopoldo B. B. da Silveira from Highplastic Indústria de Plásticos Ltda (Simões Filho/BABrazil) by technical support.

\section{References}

1. Kjellander CK, Nielsen TB, Ghanbari-Siahkali A, Kingshott $\mathrm{P}$, Hansen CM, Almdal K. ESC resistance of commercial grade polycarbonates during exposure to butter and related chemicals. Polym Degrad Stabil. 2008;93(8):1486-95. http:// dx.doi.org/10.1016/j.polymdegradstab.2008.05.011.

2. Torikai A, Murata T, Fueki K. Radiation-induce0d degradation of poly carbonate: electron spin resonance and molecular weight measurements. Polym. Degrad. 1984;7(1):55-64. http://dx.doi. org/10.1016/0141-3910(84)90030-2.

3. Araújo ES, Khoury HJ, Silveira SV. Effects of gamma irradiation on some properties of durolon polycarbonate. Radiat Phys Chem. 1998;53(1):79-84.

4. Hill AJ, Heater KJ, Agrawal CM. The effect of physical aging in polycarbonate. J Polym Sci, B, Polym Phys. 1990;28(3):387405. http://dx.doi.org/10.1002/polb.1990.090280310.

5. Pakull R, Grigo U, Freitas D. Current developments in materials technology and engineering: polycarbonates. Oxford: Pergamon Press; 1991. p. 3-110. (Rapra Review Reports; 42).

6. Bolton DH, Goetz JM, Gan D, Byers JA, Poliks B, Wooley $\mathrm{KL}$, et al. Chain dynamics in linear and hyperbranched phenol - polycarbonates. Macromolecules. 2003;36(7):2368-73.

7. Altstädt V. In intrinsic molecular mobility and toughness of polymers II. Berlin: Springer; 2005. 105 p.

8. Borisova B, Kressler J. Environmental Stress-Cracking Resistance of LDPE/EVA Blends. Macromol Mater Eng. 2003;288(6):50915. 
9. Lewis PR. Environmental stress cracking of polycarbonate catheter connectors. Eng Fail Anal. 2009;16(6):1816-24. http:// dx.doi.org/10.1016/j.engfailanal.2008.08.026.

10. Choi BH, Weinhold J, Reuschle D, Kapur M. Modeling of the fracture mechanism of HDPE subjected to environmental stress crack resistance test. Polym Eng Sci. 2009;49(11):2085-91. http://dx.doi.org/10.1002/pen.21458.

11. Wee JW, Zhao Y, Choi BH. Observation and modeling of environmental stress cracking behaviors of high crystalline polypropylene due to scent oils. Polym Test. 2015;48:206-14. http://dx.doi.org/10.1016/j.polymertesting.2015.10.011.

12. Nomai J, Schlarb AK. Environmental stress cracking (ESC) resistance of polycarbonate/SiO2 nanocomposites in different media. J Appl Polym Sci. 2017;134(43):45451. http://dx.doi. org/10.1002/app.45451.

13. Silva PPJCO, Araújo PLB, Silveira LBB, Araújo ES. Environmental stress cracking in gamma-irradiated polycarbonate: a diffusion approach. Radiat Phys Chem. 2017;130:123-32. http://dx.doi. org/10.1016/j.radphyschem.2016.08.006.

14. Bovey FA. The effects of ionizing radiation on natural and synthetic high polymers. New York: Interscience Publishers; 1958. 588 p. https://doi.org/10.1002/ange.19610731627.

15. Chapiro A. Radiation chemistry of polymeric systems. New York: Interscience; 1962.

16. Yeh SH, Chen PY, Harmon J, Lee SJ. Kinetics of hardness evolution during annealing of gamma-irradiated polycarbonate. Appl Phys. 2012;112(11):113509. http://dx.doi.org/10.1063/1.4768277.

17. Gupta SK, Singh P, Kumar R, Kumar S. Gamma radiation induced modification on physicochemical properties of Makrofol (kG and N) polycarbonate. Adv Polym Technol. 2015;34(4):21510.

18. Feizi S, Ziaie F, Ghandi M. Using polycarbonate dyed with dansyl chloride for dosimetry in radiation processing. Radiochim Acta. 2015;103(8):605-12.

19. Ravindraswami K, Kiran KU, Eshwarappa KM, Somashekarappa HM. Nondestructive evaluation of selected polymers by multiple scattering of $662 \mathrm{keV}$ gamma rays. J Radioanal Nucl Chem. 2014;300(3):997-1003.

20. Kumar A, Jain RK, Yadav P, Chakraborty RN, Singh BK, Nayak BK. Effect of gamma irradiation on the etching properties of Lexan and Makrofol e DE polycarbonate plastics. J Radioanal Nucl Chem. 2013;295(1):95-8.

21. Vujisic M, Stankovic K, Dolicanin E, Jovanovic B. Radiation effects in polycarbonate capacitors. Nucl Technol Radiat Prot. 2009;24(3):209-11.

22. Du BX, Liu HJ. The application of recurrence plot in DC tracking test of gamma ray irradiated polycarbonate. IEEE Trans Dielectr Electr Insul. 2009;16(1):17-23.

23. Loncar B, Osmokrovie P, Vujisie M, Vasic A. Temperature and radiation hardness of polycarbonate capacitors. J Optoelectron Adv Mater. 2007;9:2863-6.

24. Bailey JV, Haag E. Gamma radiation sterilization of polycarbonate. In: Proceedings of SPE Conference ANTEC; 1983; Chicago. USA: ANTEC; 1983. p. 13-5.

25. Acierno D, La Mantia FP, Titomanlio G, Calderaro E, Castiglia F. Radiation effects on a polycarbonate. Radiat Phys Chem. 1980;16(2):95-9.

26. Kurata M, Tsunashima Y. Viscosity-molecular weight relationships and umperturbed dimensions of linear chain molecules. In: Brandup J, Immergut EH, Grulke EA, editors. Polymer handbook. New York: John Wiley \& Sons; 1999.

27. Guillet J. Polymers photophysis and photo chemistry. New York: Cambridge University Press; 1987.

28. Pamies R, Hernández Cifre JG, del Carmen López Martínez M, García de la Torre J. Determination of intrinsic viscosities of macromolecules and nanoparticles: comparison of single-point and dilution procedures. Colloid Polym Sci. 2008;286(11):122331.
29. Rosen SL. Fundamentals principle of polymeric materials. New York: Wiley-Interscience; 1993.

30. Stevens MP. Polymer chemistry, an introduction. 3rd ed. New York: Oxford University Press; 1999.

31. Brandrup J, Immergut EH, Grulke EA, Abe A, Bloch DR. Polymer handbook. New York: Wiley; 2005.

32. ASTM: American Society for Testing and Materials. ASTM D638-14: standard test method for tensile properties of plastics. West Conshohocken: ASTM Internacional; 2014. http://dx.doi. org/10.1520/D0638-14.

33. Sousa AR, Amorim KLE, Medeiros ES, Mélo TJA, Rabello MS. The combined effect of photodegradation and stress cracking in polystyrene. Polym Degrad Stabil. 2006;91(7):1504-12.

34. Hama Y, Shinohara K. Electron spin resonance studies of polycarbonate irradiated by g-rays and ultraviolet light. J. Polymer Sci. 1970;8(3):651.

35. Kalkar AK, Kundagol S, Chand S, Chandra S. Effect of gamma-irradiation on structural and electrical properties of poly (bisphenol-A carbonate) films. Radiat. Phys. Chem. V. 1992;39(5):435-42.

36. Melo NS, Pondé Weber R, Miguez Suarez JC. Toughness behavior of gamma-irradiated polycarbonate. Polym Test. 2007;26(3):315-22.

37. Yang ACM, Jou ECY, Chang YL, Jou JH. The solvent-induced cracking in glassy polymer coatings by atomic force microscopy. Mater Chem Phys. 1995;42(3):220-4.

38. Wright D. Environmental stress cracking of plastics. UK: Rapra Technology Ltd.; 1996. (vol. 3).

39. Callister WD Jr. Materials science and engineering: an introduction. 7th ed. New York: John Wiley \& Sons; 2007.

40. Kambour RP. Structure and properties of crazes in polycarbonate and other glassy polymers. Polymer. 1964;5:143-55.

41. Socrate S, Boyce MC, Lazzeri A. A micromechanical model for multiple crazing in high impact polystyrene. Mech Mater. 2001;33(3):155-75.

42. De Focatiis DSA, Buckley CP. Craze initiation in glassy polymers: quantifying the influence of molecular orientation. Polymer. 2011;52(18):4045-53. http://dx.doi.org/10.1016/j. polymer.2011.06.044.

43. James MN, Christopher CJ, Lu Y, Patterson EA. Fatigue crack growth and craze-induced crack tip shielding in polycarbonate. Polymer. 2012;53(7):1558-70.

44. Moskala E, Jones M. Evaluating environmental stress cracking of medical plastics. Material Testing, Medical Plastics and Biomaterials Magazine MPB; 1 May 1998.

45. Jansen A. Understanding the consequence of ductile-to-brittle transitions in a plastic materials failure. USA: ANTEC; 2008.

46. MAKROLON $囚$. MAKROLON $®$ polycarbonate sheet is clearly the right choice [Internet]. Sheffiel Plastics Inc.; 2004 [cited 2021 July 17]. Available from: http://www.curbellplastics. com/technical-resources/pdf/polycarbonate-architect-glazingmakrolon.pdf

47. The Plastic Shop. Chemical resistance of Lexan 9030 polycarbonate sheet and lexan exell D polycarbonate sheet [Internet]. 2014 [cited 2021 July 17]. Available from: http:// www.theplasticshop.co.uk/plastic_technical_data_sheets/ chemical_resistance_guide_polycarbonate_sheet.pdf

48. Sousa AR, Araújo ES, Carvalho AL, Rabello MS, White JR. The stress cracking behaviour of poly(methyl methacrylate) after exposure to gamma radiation. Polym Degrad Stabil. 2007;92(8):1465-75.

49. Sousa AR, Araújo ES, Rabello MS. The ESC behaviour of a toughened PMMA after exposure to gamma radiation. J Mater Sci. 2009;44(4):1035-44.

50. Timóteo GAV, Fechine GJM, Rabello MS. Stress cracking and photodegradation: the combination of two major causes of hips failure. Macromol Symp. 2007;258(1):162-9. 
51. Ashter SA. Thermoforming of single and multilayer laminates. Amsterdam: William Andrew; 2014.

52. Zhang JXJ, Hoshino K. Principles, designs and applications in biomedical engineering. Amsterdam: Academic Press; 2019.

53. Pietrzyk M, Raabe D, Kozeschnik E, Miodownik MA, Nestler B. Computational materials engineering. San Diego: Elsevier; 2015.
54. Meyers M, Chawla K. Mechanical behavior of materials. Cambridge: Cambridge University Press; 2009.

55. Junisbekov TM, Kestel'man VN, Malinin NI. Stress relaxation in viscoelastic materials. Enfield: Science Publishers; 2003.

56. Hansen CM. On predicting environmental stress cracking in polymers. Polym Degrad Stabil. 2002;77(1):43-53. 